\title{
A VULNERABILIDADE DO TRABALHO DAS PROFESSORAS E PROFESSORES CONTRATADOS NA REDE BÁSICA DE EDUCAÇÃO DO ESTADO DE MATO GROSSO
}

\section{MAURÍCIO DOS SANTOS DE OLIVEIRA}

Mestrando do Programa de Pós-Graduação em Geografia da Universidade

Federal de Mato Grosso, Professor da Educação Básica do estado de Mato Grosso, Cuiabá-MT ${ }^{1}$

disanntos@gmail.com

\section{SILVIA FERNANDA CANTÓIA}

Doutora em Geografia, Professora do Departamento de Geografia e do Programa de PósGraduação em Geografia da Universidade Federal de Mato Grosso, Cuiabá-MT1 silvinhacant@gmail.com

\begin{abstract}
RESUMO: Entender os processos históricos que constituem nossa base social é necessário para que possamos analisar a contemporaneidade. Dessa maneira o objetivo deste trabalho é fazer uma leitura crítica sobre o trabalho das professoras e professores da rede básica de ensino do estado de Mato Grosso tendo em vista a pandemia do novo coronavírus. Observamos que as professoras e professores contratados correspondem a mais da metade dos profissionais que atendem a educação no estado, o grupo de efetivos ou professores que passaram por concurso público não atende a necessidade da comunidade escolar. É preciso que haja o cumprimento das leis trabalhistas para estes profissionais que vivenciaram total abandono em meio a pandemia do novo coronavírus e que seus direitos sejam preservados, assim como a abertura de novos concursos e contratações.
\end{abstract}

Palavras-chave: trabalho; professor; pandemia do novo coronavírus; educação básica; escola.

\section{THE VULNERABILITY OF THE WORK OF TEACHERS CONTRACTED ON THE BASIC EDUCATION NETWORK OF THE STATE OF MATO GROSSO}

\begin{abstract}
Understanding the historical processes that make up our social base is necessary to analyze the contemporaneity. In this way, the objective of this work is to make a critical reading about the work of teachers in the elementary school network in the state of Mato Grosso, in view of the pandemic of the new coronavirus. We observed that the interim or contracted teachers correspond to more than half of the professionals who attend education in the state, the group of effective or teachers who passed through public exam does not meet the needs of the school community. It is necessary to comply with labor laws for these professionals who experienced total abandonment in the midst of the new coronavirus pandemic and that their rights are preserved, as well as the opening of new tenders and contracts.
\end{abstract}

Keywords: work; teacher; new coronavirus pandemic; basic education; school.

\section{LA VULNERABILIDAD DEL TRABAJO DE MAESTROS Y MAESTRAS CONTRATADOS EN LA RED DE EDUCACIÓN BÁSICA DEL ESTADO DE MATO GROSSO}

RESUMEN: Comprender los procesos históricos que conforman nuestra base social es necesario para que analicemos la contemporaneidad. De esta forma, el objetivo de este trabajo es realizar una lectura crítica sobre el labor de los docentes en el sistema de educación básica en el estado de Mato Grosso, ante la pandemia del nuevo coronavirus. Observamos que los docentes interinos o contratados corresponden a más de la mitad de los profesionales que asisten a educación en el estado, el grupo de personal efectivo o docentes que aprobaron por examen público no atiende las necesidades de la comunidad escolar. Debe haber cumplimiento de la legislación laboral para estos profesionales que vivieron el abandono total en medio de la nueva pandemia de coronavirus y que se preserven sus derechos, así como la apertura de nuevas licitaciones y contratos.

Palabras clave: trabajo, docente, pandemia de nuevo coronavirus, educación básica, escuela.

${ }^{1}$ Endereço para correspondência: Av. Fernando Correa da Costa, 2367, Boa Esperança, CEP: 78060-900 - Cuiabá-MT.

Maurício dos S. de Oliveira e Silvia F. Cantóia. A vulnerabilidade do trabalho das professoras e professores contratados na rede (...) Brazilian Geographical Journal: Geosciences and Humanities research medium,

Ituiutaba, v. 11, n. 2, p. 52-69, ago./dez. 2020.

Página $\mid 52$ 


\title{
INTRODUÇÃO
}

Ao estabelecer debates sobre o trabalho e a vulnerabilidade dos profissionais contratados, delimitamos neste artigo a questão das professoras e professores da rede básica de ensino de Mato Grosso. Para isso, levaremos em consideração os aspectos políticos, econômicos e sociais, que evidenciam essa realidade.

Iniciaremos essa reflexão realizando uma breve análise sobre a educação formal no Brasil vinculada a necessidade de criação de mão de obra, e os impactos gerados e sentidos até hoje. Segundo Ribeiro (1993, p. 15),

\begin{abstract}
Na primeira metade do século XVIII, Portugal era administrado com "mão de ferro" pelo Marques de Pombal, que fez uma série de reformas educacionais que repercutiram no Brasil. Tirou o poder educacional da Igreja e colocou-o nas mãos do Estado, criando assim, um ensino pelo e para o Estado. Porém, mesmo após a expulsão dos jesuítas, em 1759, e a instauração das Aulas Regias, a situação não mudou, pois o ensino continuou enciclopédico, com objetivos literários e com métodos pedagógicos autoritários e disciplinares, abafando a criatividade individual e desenvolvendo a submissão às autoridades e aos modelos antigos. Até os professores eram, em sua maioria, os mesmos que lecionavam nos colégios jesuítas. As reformas pombalinas causaram uma queda no nível do ensino e os reflexos desta reforma são sentidos até nossos dias, visto que temos uma Educação voltada para o Estado e seus interesses.
\end{abstract}

Percebemos que ainda carregamos o fardo histórico da colonização em nossa organização escolar que traz um currículo pautado em modelos cartesianos e para o mundo do trabalho tendo em vista o viés do progresso numa visão do Capital.

Neste contexto, a profissão Professor carrega em si uma desvalorização não só do ponto de vista do salário, mas de leis e direitos adquiridos por esta categoria, os ataques são rotineiros em nosso país.

Outra questão a ser ressaltada é a heterogeneidade dos alunos e alunas em sala de aula, e os desafios enfrentados como a carência de acompanhamento psicológico, o domínio dos conteúdos referentes a série e ano e evasão escolar que fazem parte do dia a dia destes trabalhadores e trabalhadoras que atuam no chão das escolas.

Acreditamos que quando conhecemos nosso passado e a constituição de instituições como a Escola, e o objetivo de seu surgimento, ganhamos mais força para lutarmos por uma sociedade mais justa na qual os direitos e deveres possam ser compartilhados por todas e todos.

A luta é diária, e é necessário divulgarmos a situação destes profissionais em nosso país, neste período de pandemia do coronavírus a perversidade do Estado de Mato Grosso foi escancarada negando direitos já conquistados e negligenciado o direito à vida.

\section{A COLONIZAÇÃO, EDUCAÇÃO E TRABALHO NO BRASIL}

Podemos afirmar que antes da colonização do Brasil, os índios que habitavam esse território do litoral ao interior das matas densas, viviam de forma livre, havia uma simbiose entre os aspectos físicos e humanos,

Para os índios que ali estavam, nus na praia, o mundo era um luxo de se viver, tão rico de aves, de peixes, de raízes, de frutos, de flores, de sementes, que podia dar as alegrias de caçar, de pescar, de plantar e colher a quanta gente aqui viesse ter. Na sua concepção sábia e singela, a vida era dádiva de deuses bons, que lhes doaram esplêndidos corpos, bons de andar, de correr, de nadar, de dançar, de lutar. Olhos bons de ver todas as cores, suas luzes e suas sombras. Ouvidos capazes da alegria de ouvir vozes estridentes ou melódicas, 
cantos graves e agudos e toda a sorte de sons que há. Narizes competentíssimos para fungar e cheirar catingas e odores. Bocas magníficas de degustar comidas doces e amargas, salgadas e azedas, tirando de cada qual o gozo que podia dar. E, sobretudo, sexos opostos e complementares, feitos para as alegrias do amor. (RIBEIRO,1995 p. 45).

Com a chegada dos colonizadores europeus, os índios não imaginavam as mudanças que iriam acontecer, na sua forma de viver, lidar com a terra e com o meio ambiente, a sobrevivência na maioria das vezes tranquila, a cultura diversa, os hábitos simples, "eram, a seu modo, inocentes, confiantes, sem qualquer concepção vicária, mas com claro sentimento de honra, glória e generosidade, e capacitados, como gente alguma jamais o foi, para a convivência solidária" (RIBEIRO,1995 p. 45). Os índios não temiam a princípio este estranho recém-chegado pelo mar.

Os índios perceberam a chegada do europeu como um acontecimento espantoso, só assimilável em sua visão mítica do mundo. Seriam gente de seu deus sol, o criador - Maíra -, que vinha milagrosamente sobre as ondas do mar grosso. Não havia como interpretar seus desígnios, tanto podiam ser ferozes como pacíficos, espoliadores ou dadores. Provavelmente seriam pessoas generosas, achavam os índios. Mesmo porque, no seu mundo, mais belo era dar que receber. Ali, ninguém jamais espoliara ninguém e a pessoa alguma se negava louvor por sua bravura e criatividade. (RIBEIRO,1995 p. 42).

Diante da coexistência rapidamente a percepção sobre o colonizador é modificada, os índios observam que os costumes, os hábitos, a cultura dos invasores, era totalmente diferente do que eles estavam acostumados, seu modo de vida singelo e na maioria das vezes pacífico é transformado.

Mais tarde, com a destruição das bases da vida social indígena, a negação de todos os seus valores, o despojo, o cativeiro, muitíssimos índios deitavam em suas redes e se deixavam morrer, como só eles têm o poder de fazer. Morriam de tristeza, certos de que todo o futuro possível seria a negação mais horrível do passado, uma vida indigna de ser vivida por gente verdadeira. (RIBEIRO, 1995 p. 42).

O convívio com o colonizador mostrou-se terrível paro os índios, além das doenças e pestes trazidas pelo homem branco, estes ainda os escravizaram. A não aceitação desta imposição cultural provocou o genocídio de milhões.

Os índios não se renderam ao trabalho forçado e a imposição de costumes estrangeiros, pois para eles, não existia sentido nas atividades propostas, quão servidão doméstica ou mineração, causando forte resistência aos interesses dos colonizadores.

No sentido de disseminar as ideias de conquista, ocupação territorial, hegemonia cultural e apropriação das riquezas, os europeus necessitavam dos índios para executarem funções necessárias ao empreendimento colonizador, a submissão e a exploração desses povos, foi umas das alternativas implementadas, porém, esse processo causou para os índios prejuízos irreparáveis.

Assim é que a civilização se impõe, primeiro, como uma epidemia de pestes mortais. Depois, pela dizimação através de guerras de extermínio e da escravização. Entretanto, esses eram tão-só os passos iniciais de uma escalada do calvário das dores inenarráveis do extermínio genocida e etnocida. (RIBEIRO,1995 p. 42).

Várias formas de violência foram impostas aos índios, foram presos, torturados, separados de suas tribos, ameaçados, tudo para usufruir de mão de obra, já que eles nunca iriam aceitar serem escravizados. 
Para tentar melhorar a relação de imposição de poder, os colonizadores juntamente com os jesuítas, agiram de modo a catequizá-los e doutrinando-os no intuito de facilitar o domínio, em busca de promover o conformismo e a submissão para uma cultura, contrária aos seus princípios levando o indígena a colaborar com o processo exploratório imposto pelos invasores.

A catequização dos índios nas Américas e principalmente no Brasil, marca o início do desenvolvimento dos processos educacionais de uma cultura baseada na exploração, dominação e serventia, dentre os vários objetivos é possível de acordo com SILVA (1995. p.27) destacar que, "aldear índios, ensinar-lhes a língua portuguesa e mantê-los sob a orientação de missionários jesuítas asseguraria o domínio lusitano destas partes da América”.

A doutrinação dos índios ajudou na dominação desses povos, criando uma classe trabalhadora, que viria a atender os interesses dos colonizadores.

Índios aldeados e aliados é garantida a liberdade ao longo em toda a colonização, no entanto, a liberdade não era respeitada. A legislação prescrevia que os índios deveriam, quando requisitados, trabalhar mediante o pagamento de salários e deveriam ser bem tratados; porque deles dependia, também, a defesa do território. (PERRONE-MOISÉS 1992, p.117).

Observamos que os índios eram obrigados a trabalharem em ritmos e maneiras das quais eram violentados, além disso, lhes é oferecido em troca da jornada exaustiva, dinheiro, que diante de sua cultura e modo de entendimento sobre o que era trabalho não tinha sentido, portanto, mesmo com essa inconsistência de interesses, é necessário considerar que no período do Brasil colonial já se formava uma classe de trabalhadores.

Segundo Perrone-Moisés (1992, p.120),

O trabalho dos índios das aldeias é, desde o início, remunerado, já que são homens livres. Sejam as aldeias administradas por missionários ou por moradores, as leis preveem o estabelecimento de uma taxa, os modos de pagamento e o tempo de serviço. O pagamento de salário é afirmado desde a Lei de 1587 , reafirmado no alvará de 1596 , na Lei de 1611, no Regimento do governador geral do Maranhão e Grão-Pará de 14/4/1655.

A catequização dos índios, interferiu na relação com os colonizadores, pois, mesmo sem compactuarem com os pensamentos e ações que lhes eram impostas, passaram a obedecer às ordens dos colonizadores com menos resistência, estes se mantinham em cargos ou funções na hierarquia trabalhista superior aos recém-catequizados.

A catequese e a civilização são os princípios centrais de todo esse projeto, reafirmados ao longo de toda a colonização: justificam o próprio aldeamento, a localização das aldeias, as regras da repartição da mão-de-obra aldeada, tanto a administração jesuítica quanto a secular, escravização e o uso da força em alguns casos. (PERRONE MOISÉS 1992, p.120).

Temos ai o princípio das atividades educacionais no Brasil, intrinsecamente desenvolvida junto ao trabalho, no intuito de facilitar a dominação lusitana nestas terras, contudo, a grande maioria dos países que foram colônias de exploração, fornecedores de matérias primas, riquezas para o velho continente, passaram por esta situação, foi pela escravidão, exploração, catequização e pelo trabalho que se desenvolveram principalmente as nações latino americanas, em especial a brasileira.

Os países que foram colônias de exploração vivenciaram momentos históricos durante suas colonizações que deixaram sequelas profundas, foram saqueados de maneira brutal. $\mathrm{O}$ roubo desmedido dos recursos naturais proporcionados pela abundância seus aspectos físicos, a cultura dos habitantes nativos que foram agredidos e obrigados a seguir a cultura do 
colonizador, o genocídio de milhares de pessoas e o extermínio de diversas culturas são marcas que ainda ressoam em nossa história.

Os colonizadores em especial os portugueses no Brasil, tentavam de todas as maneiras impor seus ideais políticos, culturais e econômicos em todo o território conquistado, matando, escravizando, explorando os diversos recursos, alimentado o capitalismo mercantilista.

Temos como reflexo o desenvolvimento precário de nações como o Brasil, classificadas, como terceiro mundo, subdesenvolvido, categorizações que ainda carregam o traço violento que rotula e esmaga territórios tão diferentes e que possuem como dito uma história de exploração.

A imposição do tempo para o progresso econômico baseado em modelos europeus e norte-americanos esmagou a construção de uma sociedade que adotando modelos prontos, tiveram que se adaptar e com isso criar a ideia de que deveriam correr contra o tempo para não ficarem para trás, diferente de países europeus onde a transição de fases históricas, políticas e econômicas levaram séculos, como na transição da produção manufaturada para a industrializada.

Tais países vivenciaram uma transição que levou séculos, um longo processo que principiou com o artesanato, avançou para a manufatura e, posteriormente, para a grande indústria", na América Latina "esse trânsito foi muito mais rápido, pois em vários países saltou-se quase que diretamente do trabalho rural, da escravidão africana ou indígena, para novas formas de trabalho assalariado industrial que repercutiu diretamente na particularidade da morfologia da classe trabalhadora latino-americana. (ANTUNES 2011 p.11).

Assim, os processos educacionais e de exploração do trabalho se apresentam de forma inseparável na história especialmente dos países que foram colônias de exploração, sobretudo, na América Latina e no Brasil, isto causou impactos negativos no desenvolvimento social, político, econômico destas nações, consequentemente provocou a caracterização existente na classe operária, somos todos trabalhadores e trabalhadoras explorados pelo sistema político vigente, somos educados ao trabalho e a servidão sem questionamentos ou reivindicações, somos a classe que vive do trabalho.

\section{A CLASSE QUE VIVE DO TRABALHO}

Ao longo do tempo, com a primeira revolução industrial iniciada na Europa, final do século XVIII, acendem os centros urbanos, a industrialização dá impulso ao incremento dos processos produtivos, os operários assalariados, a instrução formal e inovações tecnológicas. Temos grandes transformações na organização social, dentre elas, a vinda do homem do campo para territórios urbanos, as cidades.

A falta de moradias, aumento de índices de violência, a falta de conhecimento para mão de obra qualificada, problemas sanitários, precariedade na saúde, na prestação de serviços como educação formal, atenuando as diferenças de classes e acesso ao modo de produção, consequentemente aumentando as explorações dos trabalhadores e trabalhadoras era o retrato neste período das cidades brasileiras.

Por falta de condições e qualificação e mesmo forçados pelas mudanças que ocorrem ao longo das transformações sociais, políticas e econômicas, provenientes desse período histórico, a primeira revolução industrial, os aproveitamentos e vantagens sobre os trabalhadores se perpetuam e é dinamizada com as mudanças que surgem a partir da primeira e segunda guerra mundial (1914-1938), o capitalismo continua ampliando seus tentáculos sobre a classe trabalhadora, explorando a mão de obra e se apropriando dos diferentes contextos especialmente no trabalho. 
Uma noção ampliada de classe trabalhadora inclui, então, todos aqueles e aquelas que vendem sua força de trabalho em troca de salário, incorporando, além do proletariado industrial, dos assalariados do setor de serviços, também o proletariado rural, que vende sua força de trabalho para o capital. Compreender contemporaneamente a classe-que-vive-do-trabalho desse modo ampliado, como sinônimo da classe trabalhadora, permite reconhecer que o mundo do trabalho vem sofrendo mutações importantes. (ANTUNES 2009, p. 103/104).

Em vários países do mundo e em especial no Brasil, que receberam de herança a exploração das colônias europeias, o início do sistema de ensino e a formação da classe trabalhadora desenvolveram-se pautadas em situações de exploração e precarização, que a princípio foi escravizada e violentada das diferentes formas.

Mesmo após lutas organizadas pelos trabalhadores por direitos, temos com fim da escravidão, principalmente índios e negros no Brasil, deixados sem condições de sobrevivência, para conseguirem manter o mínimo de dignidade, muitos aceitavam trabalhos pesados por valores indignos.

O Brasil transforma trabalho escravo em livre, porém, há que se pensar que o fim da escravidão também tem em seu percurso a ideia de que com a mudança na forma do trabalho, criando a ideia de liberdade, ou seja, agora assalariado, o trabalhador (a) era livre, o que eximia do patrão qualquer responsabilidade .

Esse período da história nos revela que o fim da escravidão foi um acordo para que os antigos donos de escravos tivessem mais lucro fazendo com que a população negra e indígena, agora livre, continuasse segregada, excluída.

Dando continuidade a essa sociedade marcada pela violência ao trabalhador, ressaltamos que,

No Brasil, particularmente na década de 1990, as transformações geradas pela nova divisão internacional do trabalho foram de grande intensidade, já que partiram de uma dinâmica interna, característica dos países de industrialização dependente, fundada na superexploração da força de trabalho. A imposição de baixos salários, associados a ritmos de produção intensificados e jornadas de trabalho prolongadas, foi ainda acentuada pela desorganização do movimento operário e sindical, imposta pela vigência, entre 1964 e 1985, da ditadura militar. (ANTUNES, 2010 p. 409).

Tendo em vista a superexploração da força de trabalho, baixos salários, falta de qualificação profissional, longas jornadas, desorganização sindical, continuam ocasionando situações que transformam à vida dos trabalhadores e trabalhadoras, a classe que vive do trabalho novamente se depara com circunstâncias que precarizam o labor, afirma ALVES (2009, p. 25).

O reflexo dessas mudanças produziu um processo de precarização estrutural do trabalho, com aumento do desemprego, aumento do trabalho temporário e a instabilidade, parcialidade e terceirização do trabalho. A generalização desse processo culminou na desqualificação da força de trabalho, na intensificação da jornada e do ritmo de trabalho, na adoção do processo produtivo flexível e todo o seu corolário discursivo de multifuncionalidade, por necessidade de desenvolver diferentes tarefas e aumentar a qualificação, como estratégias para usufruir da capacidade intelectual e manual do trabalhador e proporcionar maior valorização do capital. ALVES (2009, p. 25)

O reflexo de fatos históricos como o início da educação formal e as primeiras classes dos trabalhadores no Brasil, proporciona estas características, como a precarização estrutural do trabalho, crescimento das taxas de desemprego, ampliação do trabalho temporário, instabilidade, parcialidade e terceirização do trabalho. 
Neste contexto, nos deparamos com a realidade do professorado no Brasil, que passa por desvalorizações não apenas de salários, mas também intelectuais, já que são sempre atacados e estigmatizados, acirra-se neste momento, no qual vemos o avanço de governos neoliberais, com golpes severos à educação.

\title{
A VULNERABILIDADE DOS PROFESSORES E PROFESSORAS CONTRATADOS NO ESTADO DE MATO GROSSO
}

Analisando uma das classes que vivem do trabalho na educação, os professores e professoras contratados do estado de Mato Grosso, observamos claramente que as condições de desemprego, instabilidade, terceirização, longas jornadas de trabalho, baixos salários, desorganização sindical, precarização, são situações reais, presentes no dia a dia desses profissionais.

\begin{abstract}
Essas questões são duplamente vivenciadas na educação: pela adoção de novos padrões de remuneração e contratação dos professores conforme o padrão flexível e, mais ainda, pela materialização de propostas de reformas curriculares para as escolas, de políticas de formação de professores, afetando, sobremaneira, o trabalho docente. ALVES (2009, p. 25)
\end{abstract}

A precarização, a vulnerabilidade do trabalho, é uma realidade frequente na área da educação, em todo o país existem trabalhadores, professores e professoras que vivenciam condições degradantes no seu cotidiano laboral. Questionamentos precisam ser feitos e analisados.

Porque existe número maior de profissionais docentes atuando na condição de contratados? Quais as conveniências para o estado de Mato Grosso na manutenção do número destes contratos? Quais as principais consequências para os professores e professoras contratados?

Essa situação de precarização do trabalho é enfatizada em Mato Grosso observando a quantidade de docentes interinos. De acordo com dados da Secretaria de Estado de Educação, Esporte e Lazer de Mato Grosso (SEDUC, 2019), "em 2018, atuaram o total de 22.454 professores na rede estadual, desse total 13.356 com contratos temporário, e apenas 9.098 efetivos ou concursados".

Observamos que os interinos ou contratados correspondem a mais da metade dos profissionais que atendem à educação no estado, o grupo de efetivos ou professores que passaram por concurso público não atende a necessidade da comunidade escolar.

Consequentemente vive-se uma instabilidade na educação escolar, pois o trabalhador interino a cada fim de ano, não sabe onde irá atuar, muitas vezes, temos um rodízio de professores que mudam de escola, horário e comunidade, não há uma continuidade no processo de ensino aprendizagem.

Diante desta realidade é necessário perpetrar uma profunda reflexão sobre as condições de trabalho destes professores e professoras e a partir destas reflexões traçar alguns caminhos para debatermos e entendermos o modo que a precarização e a vulnerabilidade sofrida na labuta dos professores e professoras, prejudica os processos educacionais e a partir das ponderações tentar realizar análises e reflexões no sentido de evidenciar as condições do trabalho na educação, especialmente no nível do ensino básico estadual em Mato Grosso.

Respaldada pela Constituição Federal (1988), as leis estaduais permitem que exista um número maior de profissionais docentes atuando na condição de contratados, ou seja, que os professores possam ser contratados quão interinos ou temporários. Na Lei Complementar $\mathrm{n}^{0}$ 104, de janeiro de 2002, alterada pela LC 117/02/Vide LC 165/04, alteram dispositivos da Lei Complementar $\mathrm{n}^{0} 50$ de $1^{\circ}$ de outubro de 1998 , a qual dispõe sobre a carreira dos profissionais da educação básica de Mato Grosso, 
Art. 79 Em caso de necessidade comprovada, conforme Lei Complementar $\mathrm{n}^{\mathrm{O}}$ 12, de 13 de janeiro de 1992, poderão ser admitidos servidores temporários, para exercerem o cargo de professor na rede pública estadual.

$\S 1^{0}$ A admissão de que trata este artigo deverá observar as habilitações inerentes ao cargo do profissional substituído, priorizando o candidato com o maior nível de habilitação ou grau de escolaridade.

$\S 2^{\circ} \mathrm{O}$ servidor contratado temporariamente perceberá subsídio compatível com a habilitação prevista nos incisos I e II do $\S 1^{\circ}$ do art. $4^{\circ}$ dessa lei complementar e será calculado por hora de trabalho, tendo por base a classe e nível inicial. A partir dessa Lei o Governo do Estado pode contratar servidores, estes atuam na forma de interinos durante a vigência dos contratos.

Essa necessidade é comprovada quando nos deparamos com os números referentes a quantidade de escolas e alunos matriculados, de acordo com a Secretaria Estadual de Educação de Mato Grosso, “em 2019, eram 768 unidades educacionais" e segundo dados do Instituto Nacional de Estudos e Pesquisas Educacionais Anísio Teixeira, foram matriculados na rede estadual do Mato Grosso, "em 2019, um total de 387.397 alunos", com esse número de alunos é natural que a quantidade de profissionais efetivos seja insuficiente para atender a demanda.

Esse é um dos motivos para serem realizados os contratos de profissionais interinos, para atuarem na educação ao longo do ano letivo, justificando a manutenção de mais de 50\% do quadro de professores e professoras como contratados.

Existem diversas conveniências favoráveis para o estado na manutenção do número professores contratos, como a não abertura de concurso público, pois, limitando o número de profissionais concursados, o governo gasta menos com salários e direitos trabalhistas.

O interino não pode contar com benefícios como tempo de serviço, elevações ou progressões de carreira, ações que agregam valores aos subsídios, além da tão desejada estabilidade empregatícia, o que é benéfico para a vida social, econômica e emocional dos servidores, e seu direito assegurado por lei, conquistado por uma jornada de lutas no decorrer da história.

Outro fato que potencializa a sustentação dos contratos são as longas jornadas de trabalho, no Brasil e em Mato Grosso, é fato que os docentes, no desempenho de sua função, trabalham muito além da carga horária para qual são contratados, extrapolando seus horários, para dar conta de realizar um trabalho com excelência. Os professores não terminam seus afazeres quando acabam as aulas, existe uma demanda de serviços extraclasse, como a obrigatoriedade da formação continuada, os planejamentos mensais, semanais e anuais, atendimento aos familiares, coordenadores, alunos e comunidade.

É uma atribuição designada pela profissão, que nem sempre são reconhecidas na carga horária, "é quase mais uma jornada realizada fora do principal local de trabalho, isso tem muitas consequências sobre as condições de saúde, a relação com a família e qualidade do trabalho", (VIEIRA 2003, p. 51 Apud GOUVÊA 2016), essa longa jornada de trabalho, sem as devidas condições, causa o adoecimento, físico, psíquico e social dos professores, gerando o afastamento dos profissionais seja efetivos ou interinos.

Ressaltamos que no caso de licenças os profissionais em situação de contrato, não conseguem ter a mesma estabilidade dos efetivos, isto se torna um problema, pois estes não estão assegurados pelo estatuto dos servidores efetivos, não tendo os mesmos direitos trabalhistas, desta forma necessitam ser amparados pelo Instituto Nacional de Seguridade Social (INSS) e o governo estadual tem menos custos com relação a estes servidores.

Direitos importantes na forma de progressões de carreira, elevações de níveis que agregam valores aos salários, licença médica, licença maternidade, licença para qualificação, afastamentos sem ônus, aposentadoria por invalidez, aposentadoria por idade e tempo de serviço, férias e décimo terceiro pagos de forma integrais, são alguns exemplos de como a precarização e a vulnerabilidade estão presentes na profissão, pois, o interino mesmo executando as mesmas funções dos efetivos, não tem estes direitos assegurados pelo governo, 
parte deles são garantidos pelo sistema Nacional de Seguridade Social junto aos demais trabalhadores, todos amparados pela Consolidação das Leis do Trabalho.

O professorado na condição de interino tem direitos subtraídos, primeiro a instabilidade trabalhista, pois os profissionais não têm segurança na manutenção de vínculo empregatício, esse contrato pode ser rompido a qualquer momento pela parte empregadora, o Estado.

Além da precarização e a vulnerabilidade que se apresenta na vida laboral dos profissionais da educação efetivos e principalmente interinos, surgem as novas atribuições que foram sendo incorporadas às funções dos professores e professoras,

A outra forma de intensificação do trabalho dos professores condiz com os vários papéis que o professor precisa desempenhar e que estão para além de sua formação, isto é, ele desempenha funções de agente público, assistente social, enfermeiro, psicólogo, entre outras. (OLIVEIRA, 2003 Apud GOUVÊA 2016).

Estas situações mencionadas por Oliveira (2003), agregadas a falta de infraestrutura das escolas, os baixos salários, o desprestígio profissional, a violência, a indisciplina, a cobrança por resultados, a carga emocional das novas atribuições que integradas a profissão, provocam o adoecimento, os afastamentos, as licenças para tratamentos de saúde.

É um cenário que demonstra como a precarização e a vulnerabilidade do trabalho dos profissionais da educação tem aumentado no Estado, consequentemente, aumenta a necessidade de recorrer a novos contratos e devido à alta demanda de professores sem trabalho, pouco se discute, sobre a realidade dos professores que estão fora da sala de aula para tratamento de saúde.

Assim, analisamos algumas maneiras de como se estabelece a precarização e a vulnerabilidade do trabalho docente como interino, com o chamado enxugamento do Estado, característica presente na atual fase do sistema capitalista, onde o neoliberalismo impera, no sentido de consolidar cada vez mais esta conjuntura.

O neoliberalismo passou a ditar o ideário e o programa a serem implementados pelos países capitalistas, inicialmente no centro e logo depois nos países subordinados, contemplando reestruturação produtiva, privatização acelerada, enxugamento do Estado, políticas fiscal e monetária sintonizadas com os organismos mundiais de hegemonia do capital, como o FMI e o BIRD, desmontagem dos direitos sociais dos trabalhadores, combate cerrado aos sindicalismo de esquerda, propagação de um subjetivismo e de um individualismo exacerbados, dos quais a cultura "pós-moderna" é expressão, animosidade direta contra qualquer proposta socialista contrária aos valores e interesses do capital. (ANTUNES 2009 p. 187).

Tais características neoliberais de enxugamento do Estado atendem a interesses econômicos pautados ao sistema político vigente, como afirma Frigotto (1993, p.100) "o estado é intervencionista como articulador dos interesses capitalistas", não expressando nenhuma ação no sentido de consolidar o compromisso com os profissionais contratados, a manutenção destas condições trabalhistas vão ao encontro com as políticas econômicas e socais impostas pelo sistema capitalista ,negando suas obrigações de executar políticas públicas que poderiam mudar a vida dos trabalhadores do ensino, garantindo direitos que fazem toda diferença para o professorado.

\section{O trabalho frente à Pandemia do Covid-19}

A vulnerabilidade e a degradação do labor podem ser ainda mais terríveis, Freitas (1993 p.47), evidencia dois pontos para que isso ocorra, "pode-se degradar uma profissão 
basicamente por dois mecanismos, pagando pouco ou formando mal, ou melhor, ainda, as duas coisas ao mesmo tempo".

Além desses dois fatores elencados pelo autor amplia-se a estas análises a pandemia do novo coronavírus que se abateu sobre o mundo.

Em 30 de janeiro de 2020, o surto da doença causada pelo novo coronavírus constitui uma emergência de saúde pública de importância internacional, o mais alto nível de alerta da organização mundial da saúde, "então o corona entra pela porta da frente como um monstro familiar" (DAVIS (2020 p.6). Esse monstro familiar em escala global altera profundamente a rotina das populações, principalmente as que vivem do trabalho informal, contratados temporariamente, diaristas e os mais vulneráveis do sistema econômico.

Acompanhamos as notícias de que todos os setores econômicos foram afetados, desde a extração de matérias primas, agricultura, pecuária, passando pela indústria, cada grupo em escalas maiores ou menores, todos enfrentam problemas.

Neste contexto, chamamos a atenção para a prestação de serviços, o terceiro setor, pois, nem todos os trabalhadores puderam enfrentar o início da pandemia global nas mesmas condições políticas, econômicas e sociais. Uma grande parte da população mundial sofre drasticamente os seus efeitos.

Aqueles com bons planos de saúde que também podem trabalhar ou ensinar de casa estão confortavelmente isolados, desde que sigam salvaguardas prudentes. Os funcionários públicos e outros grupos de trabalhadores sindicalizados com cobertura decente terão de fazer escolhas difíceis entre renda e proteção. Enquanto isso, milhões de trabalhadores com baixos salários, trabalhadores rurais, desempregados e sem teto estão sendo jogados aos lobos. (DAVIS 2020 p. 6).

Entre os milhões de trabalhadores e trabalhadoras que estão a mercê do Estado, os professores e professoras contratados se caracterizam como vulneráveis diante da situação de pandemia.

Informações publicadas pelo Portal Gazeta Digital em $1^{0}$ de abril de $2020^{2}$, nos indicam que "no Estado de Mato Grosso mais de nove mil profissionais da educação foram diretamente afetados, pela não contratação destes para exercerem as funções laborais”, junto a estes profissionais todos aqueles que dependem deles, famílias inteiras ficaram sem seus empregos e renda.

Inúmeras informações sobre a contratação de professores e professoras temporários para a rede estadual foram divulgadas, no entanto, a própria a Secretaria de Educação admite que:

Em virtude do reordenamento escolar e do grande número de professores efetivos remanescentes, o processo de atribuição de aulas dos servidores efetivos para $02^{0}$ calendário letivo de 2020 ainda não foi concluído. Assim, considerando que o início das atividades desse calendário previsto para iniciar-se em 23/03/2020 foi suspenso em decorrência dos Decretos Governamentais $\mathrm{n}^{\mathrm{o}} .407$ de 16 de março de 2020 e $\mathrm{n}^{\circ} .432$ de 31 de março de 2020, a Secretaria de Estado de Educação não possui amparo legal para a realização de contratação temporária por ausência de fato gerador que consiste no exercício imediato das atividades laborais do contratado em sala de aula. (GAZETA DIGITAL, 2020).

Com base nos Decretos Governamentais n ${ }^{\circ} .407$ de 16 de março de 2020 e ${ }^{\circ} .432$ de 31 de março de 2020a secretaria de Estado de Educação, não realizou a contratação de interinos, pois, o ano letivo estava em processo de reordenamento e organização com atribuição dos professores e professoras efetivos, além do calendário letivo de 2020 que teria início em 23 de

${ }^{2}$ Disponível https:www.gazetadigital.com.br/editorias/politica-de-mt 01/04/2020. Acesso em: 28/08/2020. 
março de 2020, interrompidos pelos decretos, ocasionado o desemprego de nove mil profissionais.

Este calendário letivo de 23 de março de 2020 foi necessário devido à greve trabalhista efetuada a partir de 27 de maio de 2019, durando 74 dias, com o fim determinado em 13 de agosto de 2019, considerado umas das mais duradouras greves da história da educação do Estado de Mato Grosso.

Assim, o início das atividades letivas foi prorrogado por causa da greve, existia a necessidade de reposição dos dias paralisados, estendendo o fim do ano letivo de 2019 para fevereiro de 2020, como veiculado na mídia estadual,

Para as escolas que aderiram à greve, as aulas retomadas hoje ou na quartafeira (14) e o ano letivo de 2019 será finalizado por volta de 15 de fevereiro de 2020. Após essa data, haverá um período de férias de 30 dias. O ano letivo de 2020 para essas escolas começará na segunda quinzena de março. Em 2020, a Seduc terá dois calendários vigentes, um para as escolas que não aderiram à greve e que começarão o ano letivo em fevereiro e outro para as escolas que estavam paralisadas, cujo ano letivo está previsto para começar por volta de 23 de março. (Jornal Só notícias 2019³).

Diante destas informações, ressaltamos que, a greve mesmo sendo um direito constitucional dos trabalhadores, na luta por melhores condições de trabalho, tornou-se um gerador de conflitos para a contratação dos professores e professoras, pois, o ano letivo foi prorrogado garantindo a reposição dos dias de greve, consequentemente criou-se dois calendários, dividindo a categoria entre os grevistas e não grevistas, sendo uma retaliação do governo para enfraquecer a categoria e culpabilizar o movimento grevista que lutava por direitos.

Com a portaria $n^{0}$ 719/2019 a Secretaria de Educação do Estado de Mato Grosso determinou as ações para o início do ano letivo de 2020, quando os profissionais interinos que estavam nas escolas que participaram da greve, teriam suas atribuições, isto é, quando seriam realizados os contratados, foram publicados os decretos governamentais $\mathrm{n}^{\circ} .407$ de 16 de março de 2020 e $n^{\circ} .432$ de 31 de março de 2020, que estabelecem as regras a serem cumpridas durante a pandemia, impedindo as contratações,

Dispõe sobre o Calendário Escolar das unidades escolares pertencentes à Rede Estadual de Ensino, para o ano letivo de 2020, e dá outras providências. Art. $5^{\mathrm{o}}$ para as unidades educacionais da rede estadual fica estabelecido o início do ano letivo em 03.02.2020 e o término em 11.12.2020, com exceção das unidades escolares da rede estadual que aderiram ao movimento paredista que terão início do ano letivo em 23.03.2020 e termino em 22.01.2021. (PORTARIA No $719 / 2019 /$ GS/SEDUC/MT).

Essa ação do governo causou impactos econômicos, políticos e sociais, na sustentação das atividades, a classe que vive do trabalho na educação, os professores e professoras interinos, encontraram-se desempregados, sem opções para se manterem dignamente durante a pandemia, sem subsídio, sem perspectivas de ajuda por parte dos gestores governamentais.

Esses cidadãos contribuintes ativos do sistema, foram deixados de lado, sem a menor expectativa de trabalho e menos ainda de salário, esse é um grande exemplo da precarização, vulnerabilidade e proletarização do professorado, é mais um descaso com o ensino público, alunos, familiares, comunidade, com a população em geral que contribui diariamente com o pagamento de impostos e tributos.

O Estado mostra com isso sua face perversa, colaborando diretamente na massificação da vulnerabilidade e proletarização do professorado.

${ }^{3}$ Disponível https: www.sonoticias.com.br 09/08/2018. Acesso em: 25/06/2020. 
Para Enguita (1989 p.55), “a origem da proletarização docente tem início nos processos de urbanização e criação de escolas mais complexas estruturalmente, quando se inicia uma tendência de divisão e hierarquização do trabalho dos professores”, essa divisão é ocasionada pelo sistema que forma um grande número de professores, mais não oferece condições de trabalho para esses profissionais, formando grupos distintos, um grupo de efetivos, e um grande grupo de interinos e desempregados.

Ressaltamos que as atribuições dos efetivos e contratados são as mesmas, porém, a forma de acesso ao trabalho é diferenciada, provocando a desestabilidade e a insatisfação na classe que vive do trabalho educacional. Um exemplo são aqueles que participaram do movimento paredista em 2019, os profissionais efetivos, estabilizados, estão empregados e trabalhando, porém, os interinos, os professores e professoras contratados foram os mais prejudicados no pós greve, pois não foram contratados, ficaram desempregados em meio a uma pandemia, foram deixados de lado, mesmo após anos de contribuições, trabalho e dedicação exclusiva para a formação dos cidadãos.

Após a abertura do calendário do ano letivo de 2020 , os efetivos já estavam nas escolas, na semana que seriam recebidos para atribuições de aulas, o governo ciente da ação que estava por acontecer nas escolas, ou seja, a contratação dos interinos, lança o decreto $\mathrm{n}^{0} 407$ de 16 de março de 2020, impedindo que os contratos dos profissionais interinos fossem realizados.

Fica evidente que os profissionais educadores tiveram seus direitos subtraídos como afirma, Contreras (2002 p. 87) "a proletarização se constitui na subtração progressiva de uma série de qualidades que levam o professor a perder tanto o controle quanto o sentido de seu trabalho".

Sem contrato, sem salário, sem trabalho, sem perspectivas, os trabalhadores e trabalhadoras prestadores de serviço para o funcionamento do ensino, não tem respaldo trabalhistas, seus direitos são inexistentes.

Os profissionais que defrontam cotidianamente com situações problemáticas na execução das atividades educativas, vivendo as precariedades do chão das escolas, mesmo em um estado tão rico, onde os números da economia ascendem a cada ano, proporcionado pelo agronegócio, onde as contribuições por impostos são altíssimas são simplesmente descartados.

Os índices econômicos no Estado demonstram um alto potencial financeiro que o agronegócio representa para o estado de Mato Grosso, segundo o Instituto Mato-grossense de Economia Agropecuária "o valor bruto da produção de R $\$ 79,8$ bilhão em 2019, número que representa um crescimento econômico de 126,7\% nos últimos sete anos", mesmo assim os profissionais não foram contratados, ficaram sem trabalho, desamparados frente a uma pandemia.

A pandemia do novo coronavírus 19 mostrou claramente a precarização, vulnerabilidade e proletarização do professorado, os interinos que já eram prejudicados pela situação de terem seus direitos como professores suprimido, sofrem muito mais durante a pandemia, frente ao descaso do governo.

A grande questão é: quanto tempo isto vai durar? Pode ser mais de um ano e quanto mais tempo durar, mais desvalorização, inclusive da força de trabalho. Os níveis de desemprego subirão, seguramente, para níveis comparáveis aos da década de 1930, na ausência de intervenções estatais maciças que terão de ir contra o neoliberalismo. As ramificações imediatas para a economia, bem como para a vida social diária, são múltiplas. (HARVEY 2020 p.22)

Desta forma, quando o Estado se nega a amparar seus servidores, não efetuando seus contratos, não proporcionando condições financeiras para passarem com dignidade por essa pandemia, ele causa impactos que jamais poderão ser reparados, acarretando situações permanentes na vida destes servidores.

A situação desses professores e professoras, somada ao cenário incerto de retorno das atividades econômicas e educativas, coloca a categoria diante de uma situação absurdamente preocupante. 
É necessário que o Estado atenda as exigências do sindicato dos professores e garanta imediatamente aos professores eventuais, àqueles que estão sem o contrato durante o período da pandemia o piso salarial da categoria ou auxílio emergencial. É necessário utilizar-se da soberania estatal para garantir aos trabalhadores e trabalhadoras da educação, as mínimas condições de superarem este período e viverem dignamente como contribuintes sociais, pois eles servirão a sociedade quando requisitados

\section{A informalidade}

A pandemia do novo coronavírus 19, que se abateu sobre o mundo, evidenciou claramente que o poder se concentra nas mãos de uma minoria.

Essa minoria que detém a riqueza, os meios de produção, os bilionários que dominam o mundo; esse pequeno grupo tornando-se ainda mais rico durante a pandemia, que segundo a organização não governamental, Oxfam Brasil (2020), "entre 18 de março e 12 de julho, o patrimônio dos 42 bilionários do Brasil passou de US $\$ 123,1$ bilhões para US $\$ 157,1$ bilhões”, e porque isso ocorre?

Novamente nos defrontamos com padrões da sociedade capitalista que não está preocupada com a discrepância social e sim com seu acúmulo de riquezas haja vista que ações como diminuição da mão de obra assalariada, demissões, isenção de contribuições como menos impostos, acordos econômicos com o governo, são alguns exemplos de como mesmo diante desta situação catastrófica para as maiorias populacionais, a categoria que detêm o poder permanece intacto em seus benefícios.

A pandemia chega de forma diferente para as populações, evidentemente que os ricos e bilionários não sofreram seus efeitos da mesma forma que os trabalhadores assalariados, os informais e desempregados, os trabalhadores e trabalhadoras sofrem drasticamente os efeitos do vírus, aqueles que só têm a força de trabalho precisam se arriscar na manutenção de seus afazeres.

A pandemia, além de evidenciar a precária condição de saúde da maioria da população, levando mais de 155 mil pessoas a morte, até o momento, somente no Brasil, favoreceram ainda mais o distanciamento, entre ricos e pobres, patrões e empregados, estado e o povo, vemos claramente as barreiras sociais que foram levantadas nessa pandemia. A ideia de que o trabalho liberta, enriquece, enobrece, continua sendo uma motivação utópica, instituída para a manutenção do poder pelas minorias, donos do capital.

Acompanhamos a história de muitos professores e professoras no Brasil e no estado de Mato Grosso, que não partilham da motivação utópica, perderam suas ocupações laborais, sua renda. A classe que depende diretamente do trabalho, a parcela da população que por vários motivos foram para a informalidade laboral ou estão desempregados, sobrevivem sem salários fixos, sem vínculos empregatícios, no subemprego, estes têm que encarar o risco proporcionado pela pandemia diariamente,

A classe-que-vive-do-trabalho engloba também os trabalhadores improdutivos, aqueles cujas formas de trabalho são utilizadas como serviço, seja para o uso público ou para o capitalista, e que não se constituem como elemento diretamente produtivo, como elemento vivo do processo de valorização do capital e de criação de mais valia (ANTUNES, 1999, p. 102).

A grande maioria da população, os trabalhadores e trabalhadoras repentinamente se viram em quarentena, no isolamento social, seguindo regras rígidas impostas por estados e municípios, podemos citar os mais afetados como os entregadores de aplicativos, manicures, diaristas, camelôs, entre outros que atuam diretamente no contato com o outro, disponibilizando serviços informais. Antes da pandemia representavam de acordo com o Instituo Brasileiro de Geografia e Estatística (2020), 41,1\% que foram diretamente afetados com a pandemia devido ao isolamento social.

A pandemia deixa evidenciado a crise estrutural brasileira em sua composição social, política e econômica. 
Ao nos voltarmos para o estado de Mato Grosso, pensando na realidade dos professores e professoras interinos, que não foram contratados pelo governo, estes se somam a outro dado do Instituto Brasileiro de Geografia e Estatística (2020) mostrando que somente em Mato Grosso, existem atualmente " 345 mil pessoas trabalhando sem carteira assinada, enquanto 148 mil estão desempregados”, assim, a situação a vulnerabilidade, a precarização do trabalho atinge principalmente as maiorias, a grande parcela da população que vive do trabalho, aqueles que estão no dia a dia, consumindo, sobrevivendo, mantendo o estado e outras instituições funcionando.

A população representada como "coleção de seres humanos" é um trunfo, um recurso para o Estado, para as empresas, as igrejas, os partidos etc. Trunfo sobre o qual se busca a posse, a dominação, ou ainda o controle, de maneira a integrá-lo, sob diversas formas, em processos. (RAFFESTIN 1980, p. 41).

Portanto, é possível observar que as populações de trabalhadores e trabalhadoras, aqueles que mantêm os sistemas políticos e econômicos funcionando, continuam sob tutela de uma pequena parte da população que detém o poder, RAFFESTIN (1980, p. 58), "o poder visa o controle e a dominação sobre os homens e sobre as coisas", de tal modo, temos um grupo menor, os donos dos meios de produção dominando as maiorias, os trabalhadores e trabalhadoras.

A eles foram negados o direito de participarem dos meios de produção, pois a única oferta que detém é a sua força de trabalho, segundo SPOSITO (1988, p. 44)"a história da criação de uma oferta necessária à produção capitalista deve, portanto, ser a história de como os trabalhadores foram privados dos meios de produção".

A pandemia do novo coronavírus, além do massacre de milhões de vidas, incrementa a exploração dos trabalhadores, muitos foram obrigados a trabalhar com o salário reduzido, foram demitidos, aceitaram o trabalho em condições insatisfatórias causando ainda mais a divisão social.

\section{A ajuda que não chegou}

$\mathrm{Na}$ intenção de atenuar as diferenças sociais e econômicas durante a pandemia e a situação vivida pelos professores e professoras interinos, do Estado de Mato Grosso, a Comissão Constituição, Justiça e Redação da Assembleia Legislativa do Estado, aprovou e encaminhou para apreciação em Plenário o Projeto de Lei 365/220,(13 de maio de 2020) que aprova o pagamento de um auxílio emergencial de $\mathrm{R} \$ 1,1$ mil (um mil e cem reais) aos professores interinos do ensino público estadual.

Todos aqueles profissionais que participaram do processo de atribuição SEDUC 2020, que não foram contratados deveriam receber este auxilio,

Aprovado na Comissão de Trabalho o substitutivo 02 que inclui o pagamento de um auxílio emergencial de $\mathrm{R} \$ 1,1$ mil, devendo ser implementado a partir de 01 de abril de 2020 e mantido enquanto perdurar o estado de calamidade pública no âmbito da administração pública estadual, em razão dos impactos socioeconômicos e financeiros decorrentes da pandemia causada pelo agente coronavírus. (Secretaria de Comunicação Social. ALMT 05/2020)

Com a aprovação do auxílio para os professores e professoras interinos a intenção seria reduzir impactos causados pela não contratação, aprovado para ser pago a partir de 1 de abril de 2020, no entanto, isto não ocorreu.

O governo do estado, mais uma vez de posse do poder de decisão e alheio a realidade dos professores que atuam na educação do estado, alega não ter recursos financeiros para cumprir a lei, deixando de realizar suas atribuições governamentais de oferecer condições mínimas para a sobrevivência dos profissionais, mantendo os professores e professoras em condições de precariedade e vulnerabilidade. 
Diante de fatos que estão modificando globalmente a vida em sociedade existe a necessidade de pensarmos além do capital, não é somente lucro, riqueza, competições, pensar numa sociedade solidária que se preocupe e atenda às necessidades destes trabalhadores e trabalhadoras e de tantas outras pessoas que passam por situações semelhantes.

Seria utópico pensar em uma sociedade que a riqueza possa ser distribuída em forma de ações que melhorem a qualidade de vida das populações mais pobres,

Mas talvez outro vírus ideológico, muito mais benéfico, se espalhe e nos contagie o vírus do pensamento em termos de uma sociedade alternativa, uma sociedade para além do Estado-nação, uma sociedade que se atualiza sob a forma de solidariedade e cooperação global. (ZIZEK, 2020 p.43).

Chegou o momento de abandonar o tradicionalismo, o autoritarismo, patriarcalismo, pensar no próximo, nas maiorias populacionais e iniciar a metamorfose no sistema político, econômico e social contemporâneo.

À epidemia do coronavírus é uma espécie de técnica de cinco pontos para explodir um coração destinado ao sistema capitalista global. É um sinal de que não podemos continuar no caminho em que temos estado até agora, de que é necessária uma mudança radical (ZIZEK,2020, p.44).

Infelizmente, isto não será possível, uma mudança radical somente pode advir a partir de rompimentos com o sistema político, econômico e social, seria necessário transformações sociais principalmente no campo da política e educação, no entanto, existe um sistema educacional que foi concebido para atender e promover os interesses das minorias dominantes,

A educação institucionalizada nos últimos 150 anos serviu no seu todo ao propósito de não só fornecer os conhecimentos e o pessoal necessário à máquina produtiva em expansão do sistema do capital, como também gerar e transmitir um quadro de valores que legitima os interesses dominantes, como se não pudesse haver nenhuma alternativa à gestão da sociedade (MÉSZÁROS, p. 35).

Através da educação formal, imaginar, pensar ou mesmo propor alternativas para rompimento com as ideias dominantes, das minorias, seria algo incrível no campo das transformações econômicas, políticas e sociais, uma sociedade onde os direitos, os deveres, os acessos a bens e serviços seriam distribuídos igualmente entre os cidadãos, para que isto ocorra, "é necessário romper com a lógica do capital se quisermos contemplar a criação de uma alternativa educacional significativamente diferente" (MÉSZÁROS, p. 27).

\section{CONSIDERAÇÕES}

Concluímos, nesta conjuntura neoliberal o ataque aos direitos dos trabalhadores e trabalhadoras da educação que nos traz novamente em evidência a crise da educação em nosso país.

A indefensabilidade dos professores e professoras que não tiveram trabalho, não foram contratados pelo governo, evidenciam conjunturas que já eram árduas, porém, foram agravadas, intensificadas pela precarização e vulnerabilidade do trabalho. A classe que vive do labor está no momento sem condições de ofertar sua força de trabalho e os professores e professoras interinos também fazem parte desse processo.

Pensar sobre os impactos da pandemia na vida dos professores e professoras interinos e de todos os outros trabalhadores informais, entender que as famílias estão sendo desestruturadas pela morte ou pela falta de emprego, é algo necessário nesse momento. É necessário pensar no ser humano, aquele que trabalha para sobreviver, aquele que mantem o 
sistema funcionando, é algo necessário no sentido de alvitrar e efetivar políticas que atendam as maiorias das populações que estão sendo massacradas por essa situação.

Dessa maneira, acreditamos que seja necessário um novo paradigma que dê significado a Escola como território de lutas e trocas, em uma escola libertadora que em sua composição entenda os trabalhadores da educação tendo em vista todas e todos que trabalham dia a dia na sua organização.

Ressaltamos a importância das professoras e professores neste contexto de ensino aprendizagem pois são responsáveis pela transposição didática na assimilação, contextualização e entendimento de elementos teóricos e práticos vivenciados na vida em sociedade. É preciso que haja o cumprimento das leis trabalhistas para estes profissionais que vivenciaram total abandono em meio a pandemia do novo coronavírus e que seus direitos sejam preservados, assim como a abertura de novos concursos e contratações.

\section{REFERÊNCIAS}

ALVES. Ana Elizabeth Santos, Trabalho docente e proletarização. Revista HISTEDBR. Artigo Revista HISTEDBR. 2009. Universidade Estadual do Sudoeste da Bahia. Disponível em: http://www.histedbr.fe.unicamp.br/revista/edicoes/38e/reso1

Acesso em: 12 de maio 2020.

ANTUNES, Ricardo. Os Sentidos do Trabalho: ensaio sobre a afirmação e a negação do trabalho / Ricardo Antunes. - 2. ed., 10... - São Paulo, SP: Boitempo, 2009. -Mundo do Trabalho.

ANTUNES, Ricardo. O privilégio da servidão: O novo proletariado de serviço na era digital. São Paulo: Boitempo, 2010.

ANTUNES, Ricardo. O Continente do Labor. São Paulo: Boitempo, 2011.

BRASIL. 1996. Lei de Diretrizes e Bases - Lei 9394/96 | Lei no 9.394, de 20 de dezembro de 1996. Disponível: http://www.planalto.gov.br. Acesso em: 22 agosto 2020.

BRASIL. Instituto Nacional de Estudos e Pesquisas Educacionais Anísio Teixeira. Resumo Técnico: Censo da Educação Básica Estadual 2019 [recurso eletrônico] Brasília: Instituto Nacional de Estudos e Pesquisas Educacionais Anísio Teixeira, 2020.

Disponível: portal.inep.gov.br. Acesso em: 15 de agosto 2020.

CONTRERAS, J. A autonomia de Professores. São Paulo: Cortez, 2002.

DAVIS, Mike. A crise do coronavírus é um mostro alimentado pelo capitalismo. In. Coronavírus e a luta de classes. Davis M.; Harvey D.; ZIZEK S.; (org)Terra sem Amos: Brasil, 2020.p. 05-12.

DURKHEIM, Émile. Educação e Sociologia.1o ed. São Paulo: Melhoramentos, 1975.

ENGUITA. Mariano Fernández. A face oculta da escola educação e trabalho no capitalismo. trad. Tomaz Tadeu da Silva. - Porto Alegre: Artes Médicas, 1989.

ENGUITA. Mariano Fernández. A ambiguidade da docência: entre o profissionalismo e a proletarização. Teoria e Educação. Porto Alegre,1991

FREITAS, Luís Carlos. Conseguiremos escapar do neotecnicismo? A formação do professor de séries iniciais do ensino de $1^{\circ}$ grau no âmbito da política de modernização econômica no Estado de Santa Catarina. (Dissertação de mestrado), 
Florianópolis, UFSC, 1993. Disponível em: http://repositório.ufsc.br .Acesso em: o1 de maio 2020.

FRIGOTTO, Gaudêncio. A produtividade da Escola improdutiva. Cortez. São Paulo1993.

GOUVÊA. Leda Aparecida Vanelli Nabuco de. As condições de trabalho e o adoecimento de professores na agenda de uma entidade sindical Saúde Debate. Rio de Janeiro, v. 40, n. 111, p. 206-219, OUT-DEZ 2016. Disponível em: https://www.scielo.br. Acesso em: 30 de julho de 2020.

HARVEY, David. Política anticapitalista em tempos de covid 19. In. Coronavírus e a luta de classes. Davis M.; Harvey D.; ZIZEK S.; (org.) Terra sem Amos: Brasil, 2020.p. 13-23.

MATO GROSSO. Lei Complementar $\mathrm{N}^{0}$ 104, de janeiro de 2002, LC 165/04. Dispõe sobre a carreira dos profissionais da educação básica de Mato Grosso. 2002.

Disponível: http://www.al.mt.gov.br . Acesso em 23 julho 2020.

MATO GROSSO. Secretaria de Estado de Educação. Números de profissionais nas unidades educacionais do Estado. SEDUC-MT. 2018 Disponível: http://www.seduc.mt.gov.br. Acesso em 24 julho 2020.

MATO GROSSO. Secretaria de Estado de Educação. Unidades educacionais em Mato Grosso. SEDUC-MT. 2019. Disponível: http://www.seduc.mt.gov.br. Acesso em 24 agosto 2019.

MATO GROSSO. Secretaria de Estado de Educação. Portaria No 719//2019/GS/SEDUC/MT. Dispõe sobre o Calendário Escolar das unidades escolares pertencentes à Rede Estadual de Ensino, para o ano letivo de 2020, e dá outras providências. SEDUCMT. 2019. Disponível: http://www.seduc.mt.gov.br. Acesso em 10 agosto 2020.

MATO GROSSO. Projeto de Lei 365/22o,13 de maio de 2020. Assembleia Legislativa de Mato Grosso, 2020. Secretaria de Comunicação Social. Disponível em: http://www.al.mt.gov.br. Acesso em 13 de maio 2020.

MATO GROSSO-IMEA. Crescimento econômico do Estado de Mato Grosso. 2019. Instituto Mato-grossense de Economia Agropecuária. Disponível: http://www.imea.com.br/imea-site . Acessado em 15 de julho 2020.

MATO GROSSO. Decretos Governamentais $\mathrm{n}^{\circ} .407$ de 16 de março de 2020 e $\mathrm{n}^{0} .432$ de 31 de março de 2020.Dispõem sobre medidas adotadas no enfrentamento da covid19 e outras atribuições. Diário oficial do Estado de Mato Grosso. Disponível: http://www.mt.gov.br/documentos. Acesso em 30 julho 2020.

MÉSZAROS, Istvám. A educação para além do capital. São Paulo. Boitempo 2008. Mundo do Trabalho.

NOBREGA. Miriam, Medre. A contribuição da família no contexto escolar pautado na Pedagogia Histórico-Crítica. Universidade Estadual de Londrina. 2007(Dissertação de mestrado). Disponível em: miriammedrenobrega@seed.pr.gov.br

Acesso em: 10 agosto 2020.

Oxfam Brasil. Relatório quem paga a conta. 2020. Disponível em https://www.oxfam.org.br. Acesso em 27/28/2020 
PERRONE-MOISÉS, Beatriz. Índios livres e índios escravos: os princípios da legislação indigenista do período colonial (séculos XVI a XVIII). In: CUNHA, Manuela Carneiro da (Org.). História dos índios no Brasil. São Paulo: Companhia das Letras: Secretaria Municipal de Cultura: FAPESP, 1992.

Portal de notícias gazetadigital. Professores sem contrato. gazetadigital.com.br

Disponível https://www.gazetadigital.com.br/editorias/politica-de-mt 01/04/2020

Acessado em: 28 agosto 2020.

Portal sonoticias. Calendário letivo 2020. www.sonoticias.com.br. Disponível em https:// www.sonoticias.com.br 09/08/2018. Acesso em 25 de junho 2020.

RIBEIRO, Darcy. O Povo Brasileiro: A formação e o sentido do Brasil. Darcy Ribeiro. Companhia das letras. 1995. São Paulo. $2^{\circ}$ ed.

RIBEIRO, Paulo Rennes Marçal. História da Educação Escolar no Brasil. Notas para uma reflexão. Paidéia, FFCLRP-USP, Ribeirão Preto, 1993.

RAFFESTIN, Claude. Por uma geografia do poder. Título original: Pour une géographiedupouvoir Copyright (C) LITEC Paris, 1980. TRADUÇÃO Maria Cecília França. 1993. Editora Ática S.A.

SILVA, Jovam Vilela da. Mistura de cores: política de povoamento e população na Capitania de Mato Grosso - século XVIII. Cuiabá: Ed UFMT, 1995.

SPOSITO. Maria Encarnação Beltrão. Capitalismo e urbanização. Coleção repensando a geografia. $2^{\mathrm{a}}$ ed.Editora contexto. 1988. Universidade da Califórnia.

ZIZEK, Slavoj. Um golpe como Kill Bill no capitalismo. In. Coronavírus e a luta de classes. Davis M.; Harvey D.; ZIZEK S.; (org.) Terra sem Amos: Brasil, 2020.p. 13-23.

Recebido em: 23/08/2020. Aprovado para publicação em: 23/11/2020. 